\title{
Heuristics as adaptive decision strategies in management
}

\author{
FLORIAN ARTINGER ${ }^{1,3}$, MALTE PETERSEN ${ }^{1,2 *}$, GERD GIGERENZER ${ }^{1}$ \\ AND JÜRGEN WEIBLER ${ }^{2}$ \\ ${ }^{1}$ Max Planck Institute for Human Development, Center for Adaptive Behavior and Cognition, Berlin, Germany \\ ${ }^{2}$ Department of Business Administration, Human Resource Management and Organisation, Fernuniversität in Hagen, \\ Hagen, Germany \\ ${ }^{3}$ Warwick Business School, Behavioural Science Group, The University of Warwick, Coventry, U.K.
}

\begin{abstract}
Summary In the management literature, heuristics are often conceived of as a source of systematic error, whereas logic and statistics are regarded as the sine qua non of good decision making. Yet, this view can be incorrect for decisions made under uncertainty, as opposed to risk. Research on fast and frugal heuristics shows that simple heuristics can be successful in complex, uncertain environments and also when and why this is the case. This article describes the conceptual framework of heuristics as adaptive decision strategies and connects it with the managerial literature. We review five classes of heuristics, analyze their common building blocks, and show how these are applied in managerial decision making. We conclude by highlighting some prominent opportunities for future research in the field. In the uncertain world of management, simple heuristics can lead to better and faster decisions than complex statistical procedures. Copyright @ 2014 John Wiley \& Sons, Ltd.
\end{abstract}

Keywords: management; heuristics; adaptive decision making; decision strategies; ecological rationality

Uncertainty is a defining characteristic of managerial decision making. The term refers to situations in which a decision maker does not know all possible options with their consequences and probabilities. Yet the rational choice models that dominate management science, operations research, and managerial economics assume this knowledge is a given (March \& Olsen, 1986). These models deal with situations of "risk", that is, where the probabilities of outcomes are known and the optimal option can be calculated (Knight, 1921). As a consequence of this mismatch between theory and managerial reality, managers frequently should not, and do not, adhere to the procedures of rational choice (Gigerenzer, 2014; Simon, 1955). Recent research has shown that managers and firms use heuristics instead, that is, simple decision processes that only use part of the available information (e.g., Bingham \& Eisenhardt, 2011). As we will show, heuristics are not the consequence of mental shortcomings, nor do they always lead to second-best decisions, as was previously assumed (e.g., Kahneman, 2011). Rather, heuristics allow for adaptive responses to the characteristics of an uncertain managerial environment (Baum \& Wally, 2003; Khatri \& Ng, 2000).

Traditionally, research on managerial decision making has focused separately on individual decision making-exploring, for instance, topics such as behavioral decision theory (e.g., Kahneman, 1991), naturalistic decision making (Klein, 1998), and intuition (e.g., Akinci \& Sadler-Smith, 2012)—and organizational decision making - where topics such as behavioral theory of the firm (Cyert \& March, 1992), information processing (Conolly, 1977), and sense making (Weick, 1995), among others, have been studied. An important observation made in the study of managerial heuristics is that these can bridge the individualorganizational divide. This is so because the successful application of a heuristic is governed by its ecological rationality, that is, the match of a heuristic with a given environment (Gigerenzer, Todd, \& the ABC Research Group, 1999). If central environmental features that determine the ecological rationality are shared, insights from the individual domain can also hold at an organizational level and vice versa.

*Correspondence to: Malte Petersen, Max-Planck-Institute for Human Development, Center for Adaptive Behavior and Cognition, Lentzeallee 94, 14195 Berlin, Germany. E-mail: petersen@mpib-berlin.mpg.de 
In this paper, we address two questions: First, how and why can an uncertain environment provide opportunities for heuristics to perform well? The answer to this question draws on the study of ecological rationality, that is, the fit between a decision strategy and structural features of the respective environment. Second, what do we know about the adaptive toolbox - that is, the repertoire of heuristics — of a manager or a firm? To answer this question, we provide an overview about the heuristics already documented and successfully used in the managerial domain. We analyze their common building blocks, which allows us to categorize the multitude of heuristics according to a few basic principles. The discussion summarizes the insights for the use of heuristics as management tools and outlines a number of central questions and research opportunities.

\section{Heuristics: Tools for Uncertainty}

The origin of the term heuristic is the Greek word for "serving to find out or discover." Heuristics are, above all, strategies to solve problems that logic and probability theory cannot handle (Groner, Groner, \& Bischof, 1983; Polya, 1954). The understanding of the term strategy in this paper follows Payne, Bettman and Johnson's, (1992) conception of a strategy as "a method (a sequence of operations) for searching through the decision problem space" (p. 23). In this respect, a heuristic is a specific instantiation of a strategy that ignores part of the information available in the problem space. It is fast and frugal as it relies on "a minimum of time, knowledge, and computation to make adaptive choices" (Gigerenzer et al., 1999, p. 14).

As early as 1921, Knight suggested that it is particularly uncertainty that characterizes the business environment and allows for profit opportunities to emerge. In a similar vein, Simon and Newell (1958) pointed out that "there are no known formal techniques for finding answers to most of the important top-level management problems" (p. 4) because these are "ill structured". The term ill structured is similar to Knight's concept of uncertainty and refers to environments where information is incomplete or not quantifiable. To discover strategies that perform effectively in such environments, Simon turned to the human mind, studying how it operates in a context with limited information, time, and computational capacity. Simon was convinced that the mind has adapted by developing strategies that match these boundary conditions (Simon, 1956). The cumulative evidence shows that people can be very good at navigating the world using adaptive decision strategies (e.g., Alby \& Zucchermaglio, 2006; Klein, 1998; Lipshitz, Klein, Orasanu, \& Salas, 2001; Oliver \& Roos, 2005), and the merits of such strategies in the management domain have been well documented (e.g., Akinci \& Sadler-Smith, 2012; Hogarth, 2001).

The view that heuristics can be successful decision strategies has not been uncontested. Around the same time as Simon $(1955,1956)$ published his work on bounded rationality, Meehl (1954) showed in an influential study that intuitive judgments of clinicians were largely inferior to those derived from actuarial methods such as linear regression. This preceded a more critical view of human judgment that became prominent in the 1970s with the birth of the heuristics and biases research program. In contrast to Simon's use of the term heuristics to refer to successful strategies for solving ill-structured problems, in the heuristics and biases program, the founding fathers, Tversky and Kahneman (1974), used the term to refer to intuitively used mental shortcuts resulting in judgments that often violate laws of logic, probability, or other benchmarks of rational choice. The heuristics and biases tradition focuses on heuristics as inferior strategies for solving well-structured problems where optimal solutions can be determined by rational choice. The heuristics and biases literature has been influential in both economics and management research (see Bazerman \& Moore, 2008, for an overview on biases in managerial decision making).

Simon's original conception of the mind being adapted to uncertain environments features centrally in the research program on fast and frugal heuristics (Gigerenzer et al., 1999). The goal of this research program is to specify heuristics with regard to their ecological rationality, determining the environments in which particular heuristics work well, and why (Todd, 2000; Todd, Gigerenzer, \& the ABC Research Group, 2012). In contrast to the heuristics and biases tradition, the fast and frugal heuristics approach focuses on decision making in ill-structured problems that give rise to uncertainty. Within these environments, heuristics have been shown to perform remarkably well. 
The adaptive nature of heuristics can originate in individual, social, and also evolutionary learning (e.g., Boyd \& Richerson, 2005; Gigerenzer, Hoffrage, \& Goldstein, 2008). The fast and frugal research program differs on three fundamental points from the heuristics and biases tradition:

1. Computational models of heuristics. Using computational models (see subsequent discussion), researchers can make precise predictions as well as test which strategies people actually use. In contrast, the heuristics and biases program focuses on verbal labels_-such as "availability" and "affect heuristic"-while not providing specific details about the underlying cognitive processes.

2. Ecological rationality. The study of ecological rationality is a normative discipline and answers the following question: In what environment is a given heuristic more successful than other strategies, that is, better adapted? The heuristics and biases approach assumes that heuristics are generally second best, with logic and statistics as the normative benchmark. Yet in a world of uncertainty, a heuristic can be normative in the sense that it leads to higher expected performance than a more complex strategy.

3. Less can be more. The heuristics and biases program does not distinguish between risk and uncertainty. Therefore, its proponents assume that a heuristic can never be more accurate than "rational choice" (weighting and adding all relevant information). A heuristic's only advantage can be that it requires less effort. As we discuss later, this accuracy-effort trade-off is not a general law. In an uncertain world, less can be more.

Finally, in the heuristics and biases program, heuristics are aligned with automated, intuitive reasoning in the socalled System 1 (Kahneman, 2011). Yet, according to the fast and frugal view, heuristics are not necessarily unconscious. For instance, a managerial heuristic such as "Hire well, and let them do their job," which aims at a climate of quality and trust, can be relied upon unconsciously, but also consciously (Maidique, 2011).

\section{Uncertainty in the Managerial Domain}

Heuristics can be highly functional in uncertain environments, which Simon and Newell (1958) deemed the most important domain for management. March and Simon (1993) suggested that

"effective control over organizational processes is limited, however, by the uncertainties and ambiguities of life, by the limited cognitive and affective capabilities of human actors, by the complexities of balancing trade-offs across time and space, and by the threats of competition" (p. 300).

More specifically, uncertainty can arise from constant changes in technology, markets, people, costs, schedules, and quality (De Meyer, Loch, \& Pich, 2002) or the introduction of new products, services, or ventures (McMullen \& Shepherd, 2006). Uncertainty is also inherent in the entrepreneurial domain where timely decisions often have to be made without being able to rely on data from past experience (Busenitz \& Barney, 1997). Such changes or novel opportunities can be unpredictable and introduce a large degree of randomness (Levinthal, 1991; Powell, 2003; Powell, Lovallo, \& Fox, 2011). In response, organizations often operate on the basis of only limited information (Dill, 1962). This begs the question of what responses have developed in the face of such uncertain environments.

Investigating how uncertainty shapes the decision making of firms, early work by Koberg and Ungson (1987) compared the organizational structures of a multinational oil firm and a group of primary and secondary schools as representative entities of highly uncertain and more predictable organizational environments. Contrary to the expectations of the authors, uncertain environments were not characterized by more flexible organizational structures but rather by more rigid ones, and concrete operational procedures were used widely. Similarly, Busenitz and Barney (1997) found that decisions in the highly uncertain entrepreneurial domain were more likely to be based on rules of thumb than on extensive analysis of all available data. Eisenhardt and her colleagues (Bingham \& Eisenhardt, 2011; Bingham, Eisenhardt, \& Furr, 2007; Brown \& Eisenhardt, 1997; Davis, Eisenhardt, \& Bingham, 
2009) were able to test these results more carefully by identifying specific high-performing strategies. Using the computer industry as a particularly volatile environment, they showed that the most successful companies in terms of profitability were not those with the most rigid or the most flexible structure. Instead, firms that employed a structure in between these extremes performed best (Brown \& Eisenhardt, 1997). The major conclusion from their work is that the degree of structuration, or robustness and performance are related in an inverse U shape.

\section{Ecological Rationality: Why Simple Heuristics Can Perform Well}

Heuristics rely on limited information and employ simple computational mechanisms. As mentioned, they have often been regarded as second-best solutions compared with optimization models based on the assumption of the accuracy-effort trade-off that lower effort yields lower accuracy. As information search is usually costly, optimization under constraint theories search until marginal costs equal marginal benefits and hence might forego some of the potentially available information (e.g., Stigler, 1961). Note, however, that this still implies that more information is always better, apart from its costs. The accuracy-effort trade-off argument was also made in the seminal analysis of the adaptive decision maker, which suggested that a trade-off between effort and accuracy is rational for heuristics (Payne, Bettman, \& Johnson, 1993).

Surprisingly, recent research has indicated that there are a number of conditions under which there exists a less-ismore effect, where more information and computation beyond a certain point can in fact decrease performance, even if there are no costs associated with information search (Gigerenzer \& Brighton, 2009; Gigerenzer et al., 1999). Typically, the relation between effort and accuracy is U-shaped: Too little or too much effort is detrimental. For example, it might not be best for a firm to respond to new information about changes in a market immediately; instead, a certain degree of rigidity can provide a competitive edge, as the following analysis shows.

\section{Bias-variance dilemma}

A general statistical explanation for less-is-more effects in particular and ecological rationality in general is the biasvariance dilemma (Geman, Bienenstock, \& Doursat, 1992). In the heuristics and biases research program (Tversky \& Kahneman, 1974), the term bias refers to the deviation of average judgment from a "rational" norm (e.g., Kahneman \& Klein, 2009). In this view, total error = bias + noise. This contrasts with the statistical literature that investigates the role of bias when a decision maker operates in an uncertain world where an inference needs to be drawn from limited data or is faced with problems of high complexity, such as it is often the case in managerial decision making. Predictions made in such an environment are also subject to the bias-variance dilemma:

$$
\text { Total error }=(\text { bias })^{2}+\text { variance }+ \text { noise }
$$

Equation (1) summarizes a decision strategy's sources of error when making predictions. The true underlying function is not known but has to be estimated from a sample. Yet, many samples can be drawn from a population. Bias refers to the deviation of the mean across samples from the true underlying mean; variance reflects the degree of systematic variation of the individual sample means; noise refers to unsystematic variation of the data. A central element of a heuristic is that it is simple, meaning that it estimates few or no parameters and ignores the remaining information. That is, it tries to minimize variance owing to estimation error. Thus, its error in prediction comes mainly from bias and less so from variance.

To illustrate, consider the problem of a firm that has to estimate the underlying function $f(x)$ of the willingness to pay (WTP) of its customers and how frequently a given WTP occurs. To do so, the firm obtains a random sample of the WTP of its customers. Estimating the underlying function, the firm faces a choice between using a simple algorithm such as a degree 2 polynomial or a more complex algorithm such as a degree 
6 polynomial. Figure 1 illustrates how much these polynomials deviate from the underlying function when moving from a noisy environment with few observations (Figure 1(A)) to a noisy environment with many observations (Figure 1(B)), to a noise-free environment (Figure 1(C)). Generally, if a decision is based on relatively little information in a noisy environment, the best-performing strategy is relatively simple. Using a more complex strategy (i.e., with more parameters to estimate), in contrast, results in overfitting, which impedes the strategy's performance. The error is exacerbated if the strategy not only fits current information but is also used to predict future outcomes. The larger the sample size and the smaller the noise, the better the complex decision strategies perform. The principle mechanism behind this result is illustrated in Figure 1(D), which shows that more complex functions are more susceptible to error from variance, which can outweigh error from bias. Note that a well-performing decision mechanism must balance errors from bias and variance, which highlights the importance of an intermediate degree of structuration, as found by Eisenhardt and colleagues (e.g., Brown \& Eisenhardt, 1997).

A. Noise and small sample

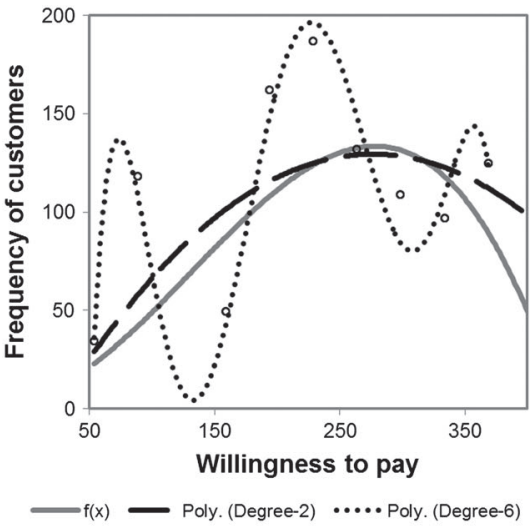

C. No noise and small sample

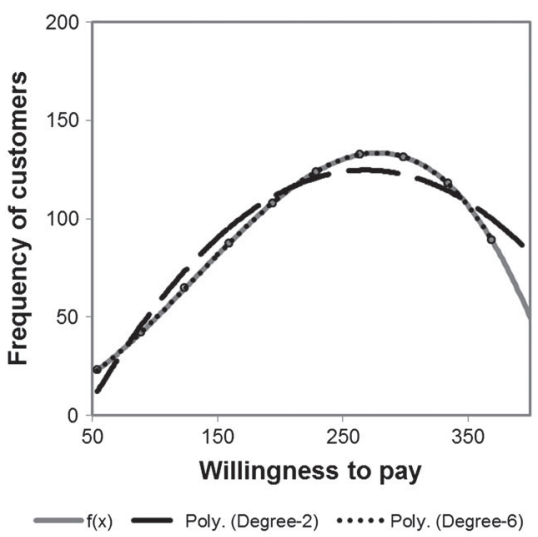

\section{B. Noise and largesample}

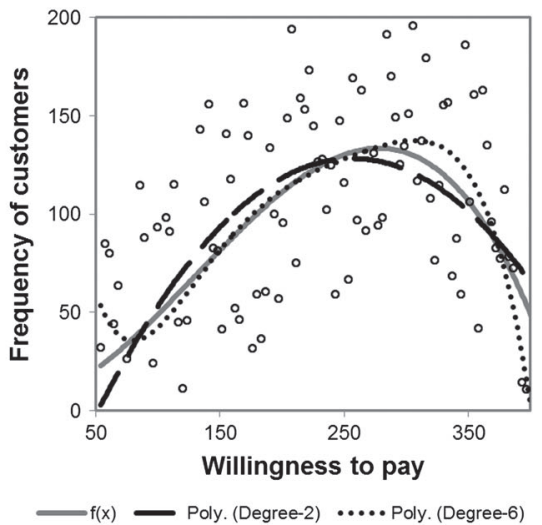

D. Error components in prediction

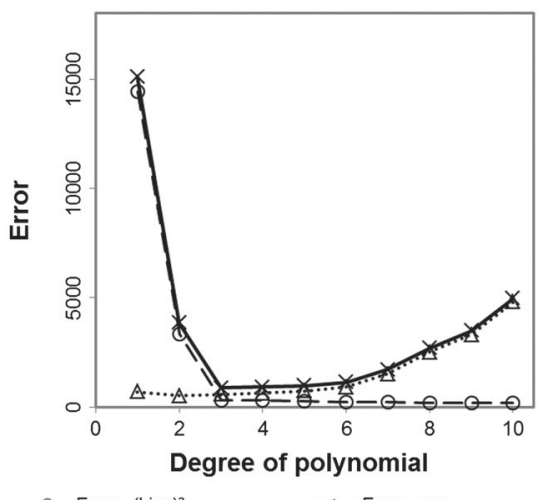

$\rightarrow-$ Error - (bias) $)^{2} \quad \cdots \bullet \cdot$ Error - var

Figure 1. Illustration of the bias-variance dilemma. In (A)-(C), the dots reflect the willingness to pay of customers, which are a random sample of the underlying function $f(x)$ represented as a solid line, the dashed line is a degree 2 polynomial, and the punctured line is a degree 6 polynomial. The environment in $(\mathrm{A})$ is noisy and provides a small sample $(n=10)$. The environment in (B) is as noisy as in (A); however, the sample is much larger $(n=100)$. The environment in $(C)$ does not contain any noise and provides a small sample $(n=10)$. (D) shows the total prediction error plus the bias and variance components depending on the polynomial 
The problem with prediction in a noisy and dynamic environment is highlighted in a study by DeMiguel, Garlappi, and Uppal (2009), who investigated the performance of a number of portfolio selection strategies. These were compared with a simple heuristic, $1 / N$, where all stocks in the portfolio receive an equal share of investment. DeMiguel et al. (2009) concluded that none of the sophisticated models that were given 10 years of stock data from which to estimate parameters were able to consistently outperform $1 / N$. Note that $1 / N$ has bias but no variance, as it does not require any parameters to be estimated. The bias-variance dilemma is a general statistical explanation of why simple heuristics can be better than complex "rational" strategies, and when less is more. In general, simple heuristics tend to be superior to complex algorithms under these conditions: greater predictive uncertainty, relatively small sample size, and less stable environment. As the investment study shows, noise in conjunction with a dynamic environment can result in simple strategies performing well despite apparently abundant data. In an organizational context, Duncan (1972) identified two dimensions that determine environmental uncertainty: the simple--complex dimension accounts for the number of factors that potentially affect a decision; the static-dynamic dimension sheds light on in how far these factors remain constant over time or are in a continuous process of change. Interviews with decision makers across a number of organizations show that a dynamic environment is a more important contributor to generating uncertainty than is complexity.

\section{Compensatory and noncompensatory environments}

Besides the trade-off between bias and variance, the very structure of the information also shapes the performance of a decision strategy. Returning to the example of the firm that has to estimate the WTP of its customers, this might depend on such cues as income, age, or education. The standard approach is to use linear regression to estimate the weights of the cues from the data to evaluate how they influence the WTP. If the company considers two versions of the product, regression analysis can be used to compute the expected WTP for each. In this case, all the available information (cues) and the respective weights are used, and no further attention is paid to the structure of the information. However, is all of this information really necessary to make good predictions, or could the firm do better by ignoring some cues?

To answer these questions, one needs to consider the information structure and to what degree it is compensatory or noncompensatory. In a noncompensatory environment, the single most important cue cannot be outweighed by any linear combination of less important cues (Martignon \& Hoffrage, 2002). For instance, income might be more important than the other two cues combined in predicting WTP. In a compensatory environment, a cue can be outweighed, or compensated for, by an individual cue or combination of other cues. In a series of articles, Hogarth and Karelaia $(2005,2006,2007)$ characterized the statistical properties of the environment and under what conditions a particular type of decision strategy performs best in prediction. They showed that even in an environment that is characterized by risk (as opposed to uncertainty) and where only noise is added, there is no all-purpose tool such as linear regression that performs best across environments. Instead, the general conclusion is that if the characteristics of a decision strategy match those of the environment, this strategy predicts best. This point is also emphasized by Simsek (2013) who analyzes 51 data sets from natural environments that cover a range of different disciplines.

An important implication of these results is that one must evaluate the ecological rationality of a strategy. This entails identifying the characteristics of an environment and precisely capturing the process of a strategy. Jointly, this allows testing its performance.

\section{Managerial Heuristics}

Tracing the chronological development, research on decision strategies in management has long focused on routines which are closely related to the notion of heuristics (Nelson \& Winter, 1982). Routines rest on an evolutionary 
process that gives rise to context-dependent, adaptive strategies emerging as a response to searching for the best action where ex ante no optimal solution can be inferred. The process of learning which decision strategy to employ in a given environment is referred to as adaptation. Central to routines is the commitment to viewing the individual agent through the lens of cognitive psychology. Routines are part of the microfoundations of the dynamic capabilities of a firm, that is, the "ability to integrate, build, and reconfigure internal and external competences to address rapidly changing environments" (Teece, Pisano, \& Shuen, 1997, p. 516). Yet recent research stresses that firms are not just driven by the accidental discovery of routines (Levinthal, 1997; Mintzberg, 1978; Nelson \& Winter, 1982). Gavetti, Levinthal, and Rivkin (2005) showed how the dynamic capabilities of a firm are jointly influenced by semiautomatic processes and calculative decision making. Similarly, Hodgkinson and Healey (2011) pointed out that explicit and implicit cognitive processes as well as emotions are essential components in the development of dynamic capabilities. A crucial difference between routines and heuristics is the amount of information used and the degree of complexity. Winter stresses that routines are "complex, highly automatic behaviors that [...] typically involve high levels of information processing" (in (Cohen et al., 1996), p. 663). In contrast, fast and frugal heuristics are simple decision strategies that function well with relatively little information.

This stresses the importance of management practitioners being aware of the different basic decision strategies that have been identified as successful tools in an uncertain environment. In this respect, knowledge of individual level heuristics can also improve decision making at the organizational level: No matter if the agent who makes a decision changes, the underlying functional mechanism and its interaction with the environment should remain the same. Notice that this assumption does not imply that heuristics at an individual level are necessarily always equal to those at an organizational level. Rather, some heuristics can apply at both levels if the central environmental features that determine the ecological rationality are shared. Heuristics at the individual level are, however, often implicit and need to be sufficiently formalized before they can be employed at an organizational level (Manimala, 1992). The transfer between these two levels is therefore not always a trivial task and requires identifying the functional principles and boundary conditions.

The use of heuristics in management has been documented for a broad range of decisions. However, the specification of different heuristics varies greatly, with the most basic form reported being mere verbal statements of rules of thumb. A large collection of such verbal heuristics was documented by Manimala (1992) in a study on pioneering innovative ventures. These include, among others, "start small, grow big organically," "minimize initial investments," "repeat successes to take full advantage of them," and "sharing is the way to loyalty and prosperity. Give everyone his due." Coleman, Maheswaran, and Pinder (2010), who have worked on narratives for decisions in corporate finance, listed a number of similar verbal heuristics, such as "focus on keeping it simple and understand what are the fundamental things you have got to get right." Verbal approaches such as these can provide valuable insights into how heuristics are part of everyday managerial decision making. However, these approaches share the problem of producing a large unstructured body of very specific heuristics without stating when and why they perform well. Different attempts to systematize this knowledge have been made. Bingham and Eisenhardt (2011) distinguished between heuristics for exploiting business opportunities and heuristics that allow linking different business opportunities. Reijers and Liman Mansar (2005) classified heuristics according to the specific nature of classic business processes. Guercini (2012) proposed sorting heuristics according to the degree of transferability between different contexts or how widespread the use of a particular heuristic is within a reference group.

Meanwhile, in psychology, considerable effort has been invested in specifying generalizable and testable descriptions of heuristic decision processes. Research on the application of heuristics in management can benefit from drawing on these established insights. Psychologists have systematized heuristics by studying, among others, common building blocks. Gigerenzer and Gaissmaier (2011) defined three such building blocks: search rules that state where to look for information, stopping rules that state when to stop searching, and decision rules that state how to decide given the attained information. In the literature, we were able to identify a number of well-specified managerial applications of heuristics that can be traced back to five basic classes of heuristics where the respective building blocks have been specified. 


\section{Satisficing}

In Simon's (1955) seminal article on bounded rationality, he highlighted satisficing as an important strategy for decision making. Maximization refers to finding the optimal solution, which is by definition not feasible in an uncertain world; satisficing, in contrast, refers to the realistic goal of finding a "good enough" solution. The term satisficing is also used for a specific strategy whereby decisions are made by setting an aspiration level, which can be fixed or adjusted (Selten, 1998). The fixed aspiration level strategy can be formulated as follows:

Search rule: Set an aspiration level and search through objects.

Stopping rule: Stop search when the first object meets the set aspiration level.

Decision rule: Choose this object.

Operating with a fixed aspiration level reduces error due to variance in the sample. Adjusting the aspiration level would reduce error due to bias.

When managing a customer base and determining future purchase volume or the future best customer, managers across Europe, North America, Japan, Brazil, and India rely on a simple satisficing strategy: If a customer has not purchased within a certain fixed time interval, they classify the customer as inactive. Wübben and von Wangenheim (2008) compared the so-called optimization models with this simple heuristic and found that the heuristic consistently performed at least as well as or better than the optimization models across a number of different industries. Note that by relying on only a fixed duration, the strategy ignores information such as frequency of purchases. The central problem that the more sophisticated models encounter is the estimation error generated from the noise in the data.

When deciding on where to locate a new business, Berg (2014) showed that successful entrepreneurs rely on a surprisingly small consideration set that is due to a low aspiration level. As a result the consideration set is much smaller than predicted by traditional models that weigh marginal search costs and marginal benefits. In the 49 cases investigated, the location choice was almost exclusively based on an aspiration level that ignores the total number of feasible options and does not update during the search process.

Strategies with adaptive aspiration levels have also been used. Lant (1992) investigated how organizational goals are set by a group of top managers in a simulated organization. The descriptive validity of an adaptive aspiration level strategy was compared with that of rational expectations. The study showed that aspiration levels provide the most robust account for organizational goal setting. In line with Lant (1992), Levitt and March (1988) found that if behavior quickly adjusts in response to feedback, organizational performance drops, particularly if information has a large error component; this pattern is also implied by the bias-variance dilemma. Using field data from American financial service organizations, Mezias, Chen, Murphy, and Patrice (2002) replicated the earlier findings by Lant (1992) that were obtained in a controlled setting.

Investigating the pricing strategies of used car dealers, Artinger and Gigerenzer (2012) showed that prices are adjusted downward at regular time intervals until a car is sold, reflecting the adjustment of aspiration levels. Dealers who used a pricing strategy closer to the conventional prescription of rational choice theory and adjusted prices quickly in response to changes in the market performed worse in terms of profit earned than those dealers who used a fixed time interval before reducing the price. This finding was further supported in a simulation study carried out by $\mathrm{Hu}$, Blettner, and Bettis (2011), who showed how the selection of proper reference groups and dynamic adaptation of aspiration levels can lead to superior firm performance in terms of higher generated wealth.

\section{Tallying and $1 / N$}

In the 1970s, researchers compared the predictive power of linear regression models, replacing the estimated weights with random or equal weights and maintaining only the appropriate sign (Dawes \& Corrigan, 1974; 
Einhorn \& Hogarth, 1975). The strategy simply counts the number of cues favoring one alternative over another and can be formulated as follows:

Search rule: Search through cues in any order, add positive cues to the tally, and deduct negative cues from it. Stopping rule: Stop after $\mathrm{n}$ cues (where $\mathrm{n}$ can be any number up to the complete set of cues).

Decision rule: Decide for the alternative with the higher tally. If after searching through all cues there is a draw, guess.

To the surprise of many, tallying can perform remarkably well. Analysis has shown that in the process of estimating the weights of a regression, the variation in the data inherent in any sampling process leads to substantial imprecision when forecasting. Tallying therefore introduces bias by ignoring the weights. Czerlinski, Gigerenzer, and Goldstein (1999) tested tallying against multiple linear regression by crossvalidation and found that the regression models had a greater fit to the data than equal weighting but a lower predictive accuracy. Equal weighting, also referred to as tallying, appeared in a similar form in the portfolio selection study of DeMiguel et al. (2009) labeled as $1 / N$, that is, investing an equal share across the stock options. The importance of the ecological rationality of a strategy was stressed by Hogarth and Karelaia (2007), who formally showed that tallying performed best compared with a number of other strategies in a compensatory environment.

Åstebro and Elhedhli (2006) investigated the performance of a heuristic strategy that combines tallying with fixed aspiration levels to forecast the commercial success of early-stage ventures. A total of 561 applications were submitted for funding containing 37 attributes (e.g., price and safety). Using 383 applications, they computed a fixed aspiration level: The number of positive attributes needs to exceed the aspiration level $p$, and the number of negative attributes must not exceed the aspiration level $n$. Separately adding positive and negative attributes without considering weights reflects the use of tallying. This was then employed to predict the success or failure of the remaining 178 submissions. Comparing the heuristic with a log-linear regression, they found that both correctly classified the same number of outcomes. Yet, the heuristic was more successful in identifying successful ventures, which were 10 times less frequent than failures and thus were much harder to identify.

Albar and Jetter (2013) showed that ignoring weights can be an effective strategy when evaluating new product ideas. Using a simulation study with partially missing data, they tested the effectiveness of fast and frugal heuristics against a number of computationally more intensive models in identifying profitable ideas. They found that tallying performed as well as a regression model with a rate of about 80 percent correct classification of successful and unsuccessful ideas.

The use of equal weighting is analogous to distributing resources equally across different units. Within the managerial domain, such a strategy can be applied, for instance, to a collaborative production process if it is difficult to account for an individual's contribution (Messick, 1993; Messick, 1999). Instead, the involved parties receive the same payoff, which often is conceived of as a fair allocation. As Lind and Kulik (1993) as well as Konovsky (2000) have shown, perceived fairness serves as a heuristic for judging whether the requests of collaborating businesses or the demands on an organizational unit are legitimate. Jones and Martens (2009) found that perceived distributional fairness is an important determinant of affective commitment and job satisfaction, thus contributing to the success of firms.

\section{Lexicographic strategies}

Elimination by aspects (Tversky, 1972) and take the best (Gigerenzer \& Goldstein, 1996) are lexicographic heuristics that implement sequential decision making. For brevity, we focus on take the best, which orders cues by decreasing validity. The validity of a cue is the number of correct decisions divided by all decisions made by this cue, and it can be estimated from a sample. A positive cue value points to the object with the higher criterion value, such as the product associated with the higher WTP. Take the best proceeds as follows: 
Search rule: Order cues by their validity.

Stopping rule: Stop on finding the first cue that discriminates between the alternatives.

Decision rule: Choose the alternative with the higher cue value.

Katsikopoulos, Schooler, and Hertwig (2010) compared the predictive accuracy of take the best with tallying, given very small samples to estimate cue validities. Tallying performed best for the minimal sample size of two; when the sample size was increased to three or more, take the best performed better. This is spurred by the heuristic ignoring the interdependencies between cues and their joint effect on the dependent variable. For instance, income and age might be interdependent in predicting WTP. Lexicographic strategies introduce bias in the decision strategy by ignoring the interdependencies between cues as well as any cues that have a lower cue validity than the discriminating cue. Constructing a computationally more intensive version of take the best that tries to estimate these interdependencies can reduce its performance by capturing more of the variance inherent in the sample (Brighton, 2006). In line with the idea of matching strategy to the environment, Hogarth and Karelaia (2007) found that take the best was the best-performing strategy in noncompensatory environments. More generally, lexicographic strategies have also been found to guide managerial pricing strategies for certain consumer products (Rusetski, 2014) and also decision making on the consumer side particularly for complex products (Ford, Schmitt, Schechtman, Hults, \& Doherty, 1989; Kohli \& Jedidi, 2007; Yee, Dahan, Hauser, \& Orlin, 2007).

Surprisingly few cues are used when a venture is evaluated. Achleitner, Lutz, Mayer, and Spiess-Knafl (2012) showed that the decision to invest in social ventures depends on two cues, voluntary accountability efforts and reputation. A positive evaluation of one of these two cues was already sufficient to obtain funding. Guercini (2012) reported that entrepreneurs in the Italian fashion industry rely on only one cue - the price of natural fibers - to predict the following year's most demanded fabrics and were remarkably consistent in their forecasts. Take the best also featured in the study on screening new product ideas by Albar and Jetter (2013). With a rate of 55 percent accuracy in correctly classifying successful and unsuccessful ideas, the performance was clearly below that of other competing strategies such as tallying and regression. However, in 92 percent of all cases, take the best relied on only one cue. It therefore could be beneficial in a context where data are scarce and more complex models are therefore likely to perform worse.

\section{Recognition}

Early on, the capacity for recognition featured centrally in studies of expert decision makers, such as chess players (Chase \& Simon, 1973). Recognition-based decicions describe situations where "the mere recognition of an object is a predictor of the target variable" (Gigerenzer \& Goldstein, 1996, p. 653). Klein, Calderwood, and Clinton-Cirocco (1986) in a now classic study investigated how fireground commanders, who operate under uncertainty and time pressure that prohibit the generation and comparison of options, make good decisions. The commanders used recognition-based decision making informed by a large repertoire of experiences. This strategy has been found in many other real-world decision-making contexts, such as system design and the management of offshore oil installations (for a review, see Klein, 1998). Goldstein and Gigerenzer (2002) competitively tested the recognition heuristic, pitting it against computationally more extensive strategies by formalizing it as follows:

Search rule: Search for an object that you recognize.

Stopping rule: Stop as soon as one object is recognized.

Decision rule: Infer that the recognized object has the higher value with respect to the criterion.

Their study and many subsequent ones across a wide range of tasks showed that the recognition heuristic can be a very effective decision strategy, illustrating that under some circumstances ignorance can be bliss (Gigerenzer \& Goldstein, 2011). The recognition heuristic incurs bias by searching for only a specific pattern or cue stored in memory and does not aim to assess values of other objects. 
In the managerial domain, recognition is an important feature of venture creation (Bhave, 1994). Specifically, Baron and Ensley (2006) suggested that new ideas for products or services emerge from recognizing patterns that present novel opportunities. Testing this idea with novice and serial entrepreneurs, they found that for both groups, recognition plays a central role in the identification of business opportunities. Its successful application is considerably strengthened by prior entrepreneurial experience. Identifying a new business opportunity frequently does not rely on public information but rather on sources that are accessible to only a few, such as personal contacts, specialized publications, or specific experiences (Hills \& Shrader, 1998). A decision process that relies on recognition might appear to be limited to individual decision making, but this does not have to be the case. Lumpkin and Lichtenstein (2005) argued that such a process can also be formalized and become part of organization decision making. Entrepreneurship is an important form of strategic renewal that is significantly aided by organizational learning (Lei, Slocum, \& Pitts, 1999). Setting up structures such that there is a tangible process of active and passive search, alertness, and prior experience in key positions guides opportunity identification and strategic renewal of a firm.

\section{Similarity}

Firms often have to make decisions in novel environments. An important source of knowledge for managerial decisions in such contexts comes from similar instantiations (Osgood, 1949; Thorndike, 1931; for a review, see Medin, Goldstone, \& Gentner, 1993). Such knowledge can stem from managers' own experiences or is gained, for instance, from case studies, probably the most popular form of business education. Using similarity implies identifying a source that shares central characteristics with a target. Read and Grushka-Cockayne (2011) formalized this in the similarity heuristic for the case when the decision maker has to identify a target object that is more similar than objects from a reference class:

Search rule: Search for an object that is more similar to the target than objects drawn from a reference class. Stopping rule: Stop as soon as a more similar object is found.

Decision rule: Infer that the identified object has a higher criterion value than those from a reference class.

Similarity judgments incur bias because they rely on a match with a target instead of trying to estimate the exact value of each object. An important open issue discussed in the literature is how to identify the object characteristics to be compared, which is the very input needed for similarity judgments (e.g., Murphy \& Medin, 1985; Tversky, 1977).

In managerial decision making, research to date has explored how similarity informs analogical reasoning in strategic decision making. Firms are embedded in complex interdependent systems that require nuanced choices (Porter, 1996; Rivkin \& March, 2000; Siggelkow, 2002). Precisely in this context, rational choice is least likely to yield clear-cut and effective decisions owing to numerous interdependent strategies creating a vast computational load, just as in the case of chess (Simon, 1955). Gavetti et al. (2005) investigated the power of analogical reasoning, which is commonplace in strategic decision making. Its successful use has been documented for companies such as Merrill Lynch (Perkins, 1999) and Toys "R" Us (Stemberg, 1996), but it can be problematic if decisions are based on superficial similarity of source and target characteristics, as was the case in the demise of Enron (Salter, 2003). Akin to pattern recognition in chess, analogical reasoning involves (i) recognizing characteristics in a source that are shared with the target and (ii) evaluating the similarity of these characteristics. Using an agent-based simulation, Gavetti et al. (2005) implemented a lexicographic strategy in which agents initially ranked the characteristics according to importance. Agents then proceeded to compare source and target by starting with the most important cue and, only if this cue was sufficiently similar, repeated the procedure for subsequent characteristics. Interestingly, Gavetti et al. (2005) showed that marginal returns are larger from breadth than from depth of experience.

The problem of superficial similarities was stressed by Lovallo, Clarke, and Camerer (2012) who suggested the use of multiple sources for a reference class instead of only one. If multiple sources are available, a challenge is 
how to select among them and how to weight them. Lovallo et al. (2012) suggested a distribution-based approach that seeks to enlarge the sample and combine this with similarity weighting that the expert decision maker assigns. The importance of sample size is an essential feature of the bias-variance dilemma; the greater the sample size drawn from the reference class, the less susceptible a strategy is to the variance in the information. In line with this, Gary, Wood, and Pillinger (2012) showed that superficial similarities can be markedly reduced if the available sources show a sufficient degree of variation in relevant characteristics and thus provide an opportunity for more complex structural relationships to be discovered.

\section{Discussion}

This review synthesizes current work on adaptive heuristics in the managerial context. It shows that the study of individual decision making can be a valuable starting point for revealing a basic set of heuristics that can be used as adaptive strategies in the managerial context. A central feature of studies on adaptive managerial strategies is that they are based largely on real-world decisions made in uncertain environments. This research illustrates the power of simple decision mechanisms and contributes to a more practitioner-oriented perspective that has been repeatedly called for by, among others, the recent strategy-as-practice movement (Vaara \& Whittington, 2012). Moreover, this approach offers ample opportunities for further basic and applied research such as on the set of basic heuristic principles, the interaction between heuristics and the managerial environment, the creation of formal tools for organizational application of heuristics, and an integration of insights from different research programs.

\section{Basic heuristic principles}

Research in the field of judgment and decision making has put much effort into studying general characteristics of basic classes of heuristics. Within the managerial domain, in contrast, research has had a more practitioner-oriented focus of identifying a large number of verbal rules of thumb that are actually used by managers. This review has shown that decision strategies in management often rely on a basic set of heuristic principles, such as satisficing, tallying, and recognition. These could serve to systematically classify the large number of verbal heuristics. For example, the verbal rule "start the first venture on a small scale" (Manimala, 1992) can be classified as satisficing; "don't put all your eggs in one basket" (Manimala, 1992) as a case of $1 / N$; "only enter English-speaking markets" (Bingham \& Eisenhardt, 2011) as similarity; "choose tried and tested products" (Manimala, 1992) as a case of recognition; and "sequence new product introductions by country" (Bingham \& Eisenhardt, 2011) as a lexicographic strategy. Bingham et al. (2007) stressed that the formalization of heuristic processes is an important determinant of long-term firm success. A precise formulation not only allows specifying why and when a heuristic performs well but also facilitates the sharing of such a decision rule across different business units and generations of managers. Maitland and Sammartino (2014) examined the decision process of an inexperienced multinational when evaluating whether to acquire a company in a politically hazardous African country. In this complex and uncertain environment, they showed that precisely specifying heuristics in terms of search, stopping, and decision rules is of great advantage to evaluate the performance of the different available decision strategies.

The study of verbal rules might also challenge the conventional perception that different heuristics constitute exclusive categories. Similar to Åstebro and Elhedhli (2006) but also Gavetti et al. (2005) these studies show that some decision strategies combine different basic heuristics, such as tallying and satisficing, and how a lexicographic strategy can inform similarity judgments. A possible way to discover such combinations could be the study of expert decision making and verbal heuristics, which can both give deeper insights into a range of commonly applied decision strategies. This may also broaden our understanding of the underlying basic heuristic principles and their interrelation. 
Considering the basic set of heuristics so far investigated, research was originally focused mostly on cognition and less on emotions (e.g., Gigerenzer et al., 1999; Klein, 1998; Tversky \& Kahneman, 1974; but see also Muramatsu \& Hanoch, 2005; Slovic, Finucane, Peters, \& MacGregor, 2007). In a programmatic assessment, Hodgkinson and Healey (2011) outlined the building blocks of emotionally informed heuristics that can be part of the microfoundations of dynamic capabilities. Affective signals can be utilized as informational components of a decision strategy to direct attention to problematic outcomes. Case studies of the London Stock Exchange, Polaroid, and other firms have shown that in an uncertain environment, corporate culture strongly affects whether managers share their unease that originates from affective signals (e.g., Drummond, 2001; Hodgkinson \& Wright, 2002; Oliver \& Roos, 2005; Tripsas \& Gavetti, 2000). At the same time, this raises the question of whether emotional components would be necessarily limited to individual decision making.

The broadening and deepening of an understanding of a set of basic heuristics also calls for determining the conditions under which a heuristic can travel from the individual to an aggregate organizational level of decision making. We have outlined a strong connection between the two levels of analysis, especially as uncertainty is a defining element of the decision environment at both levels. However, as pointed out by Powell et al. (2011), the dynamics of decision making at the organizational level can also be quite different from the dynamics at the individual level. Specifying the boundary conditions under which a heuristic is confined to one of the two levels is therefore an important issue.

\section{Interactions between heuristics and managerial environments}

A major lesson from this review is that heuristics are not general-purpose tools but rely on a match with the environment. Not only the evolutionary approach by Nelson and Winter (1982) but also research streams such as systems thinking highlight that organizations are embedded in a dynamic context where decision strategies and environments mutually influence each other (see Mingers \& White, 2010, for a review). A particular heuristic might be successfully employed for a given time. The application of this heuristic itself, however, could influence the environment up to a point where the heuristic becomes maladapted. One example of such dynamic interactions are leader-follower relationships. A leader might be able to successfully adapt to an organizational environment with a given population of followers. Over time, an adaptation process on the side of the followers can however change the effectiveness of the leader's heuristics and therefore at some point require a change of strategy. A similar situation could arise as a market evolves and fundamental characteristics of an environment change. The question of how individuals initially select a heuristic and under what conditions they switch is therefore essential. Recent research has suggested that a selection process is not only governed by reinforcement learning (Rieskamp \& Otto, 2006) but that directed search driven by cognitive representations or natural limits of available options can also play an important role (Gavetti, 2005; Marewski \& Schooler, 2011). However, research on the use of management tools in general has shown that once a particular tool is adopted, it is often persistently used within an organization independent of changes in the environment (Jarzabkowski \& Kaplan, 2014). Not only the question of how heuristic strategies are initially selected but particularly how they are switched after they have become maladapted largely remains a central but not yet sufficiently answered question.

Whether a firm's competitive advantage erodes also depends on how easily its dynamic capabilities, which also rest on the heuristics employed, can be imitated. In particular, simplicity can invite imitation and therefore might not provide a sustained competitive advantage (Rivkin \& March, 2000). Owing to path dependence of the development of the firm, competences come in strongly complementary packages that hinder imitation (Levinthal, 1994; Teece et al., 1997). The discussion on opportunity recognition has also shown that specialized information and expertise can often give a decisive first-mover advantage; this can also be fostered by the speed of the decision-making process, which is aided by its very simplicity (Baum \& Wally, 2003). A defining element of the context in which heuristics work well is an uncertain environment. This, in turn, reduces the 
likelihood that firms imitate, as their expectations about future returns can vary, for instance, owing to differing skills and capabilities (Barney, 1986). Such path dependency and how this interacts with basic heuristics has received scant attention in the literature.

\section{Tools for organizational application of heuristics}

The very use of well-adapted heuristics in an uncertain environment can be further aided by the use of formal managerial tools. Decision trees have been used as aids in management for some time (see, for instance, Vroom \& Yetton, 1973). With $n$ binary cues, the number of leaves is $2^{n}$, which implies that as the number of cues grows, a tree covering all possible options quickly becomes computationally intractable or error prone, as one has too little data with which to estimate the many possible leaves. With an exit at every level, a fast and frugal tree has only $n+1$ leaves, which makes it tractable and more robust (Luan, Schooler, \& Gigerenzer, 2011; Martignon, Katsikopoulos, \& Woike, 2008). To show an example of such a tree, we make reference to the judicial domain (Figure 2). Dhami (2003) observed several hundred court cases in London. She found that a fast and frugal tree as depicted in Figure 2 could predict 92 percent of magistrates' decisions in one court and 85 percent in another. Despite the promising performance of fast and frugal trees, their descriptive validity has not been investigated in a managerial context; it also remains to be tested if decision trees used in actual managerial decision making perform better than simple fast and frugal trees.

The power of heuristics can likely be further strengthened by combining them where appropriate with computationally more intensive decision aids. For example, Blattberg and Hoch (1990) integrated intuitive managerial decisions and decision support systems, such as statistical models, for the case of predicting sales. They argued that in a dynamic environment, models are too consistent and, for instance, cannot pick up cues that might have high predictive validity but occur only rarely. Such cues can be readily identified by experts. The results show that combining expert intuition with a statistical model improves predictive accuracy considerably.

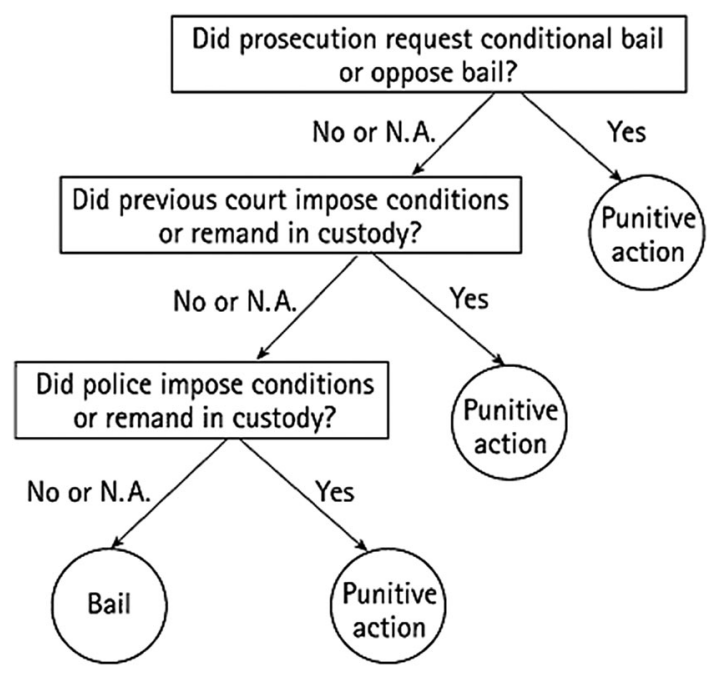

Figure 2. How magistrates at a London court determined whether to bail or to react punitively by imposing conditions such as curfew (Dhami, 2003) 


\section{Integration of insights}

In the introduction, we touched briefly on the heuristics and biases research program. Its positive contribution was to demonstrate that decision processes do not follow the rational choice approach; rather, people (including managers) often rely on simple decision strategies or heuristics (e.g., Bazerman \& Moore, 2008). However, its proponents did interpret this result above all as a weakness rather than a strength of human judgment. One case in point is the work by Mezias and Starbuck (2003) who found that managers have an inaccurate perception of some key performance indices of their companies and the market (see also Ben-David, Graham, \& Campbell, 2013). Having a firm grasp on information seems to be an important element when aligning the strategies of a company with an uncertain environment (Lawrence \& Lorsch, 1967). However, Mezias and Starbuck (2003) also noted in their discussion that performance might not necessarily depend on accurate knowledge of the current situation. Rather, firms need to pursue a general, long-term goal with the opportunity to learn from feedback. Such reinforcement learning might work well specifically in inherently dynamic and noisy environments where past information has only limited predictive value for future outcomes. The DeMiguel et al. (2009) study of the stock market is an impressive illustration of how even large amounts of precise information of the past might sometimes be insufficient to make good decisions. More generally, the heuristics and biases research program provides ample observations of situations where people ignore information. Instead of interpreting this as necessarily a second-best strategy, one also could ask whether the observed behavior might in fact result from a well-adapted heuristic.

\section{Conclusion}

Managers often have to make decisions in an uncertain environment with limited information and time constraints owing to competitive pressure. We have reviewed the research on adaptive decision strategies in the managerial context. A number of these strategies link to a basic set of heuristics that have been widely discussed and analyzed, particularly in the psychological literature. Specifically, in a noisy environment with limited information at hand, a complex decision algorithm incurs error in prediction owing to being overly sensitive to variance in the data. A simple heuristic instead incurs error in prediction owing to its bias but is much less sensitive to fluctuations in the environment, which can make it a robust and high-performing strategy. It is important to recognize that heuristics are not all-purpose tools but strategies that can perform well in particular environments. This is why a manager or an organization has an adaptive toolbox of heuristics, not just a single one. A broad recognition of the importance of the ecological rationality of a decision strategy has the potential to significantly further research on managerial decision making beyond the traditional rational choice models that still dominate current decision theory.

\section{Author biographies}

Dr. Florian Artinger is a research fellow at the Max Planck Institute for Human Development. Prior to joining the MPI, he worked as a Leverhulme research fellow at the Behavioral Science Group, Warwick Business School. He obtained his PhD in economics in 2012 from the Max Planck Institute and has been a visiting research fellow at the University of Oxford and University of Chicago.

Malte Petersen is a scientific staff member at the University of Hagen (FernUniversität in Hagen) and a guest researcher at the Max Planck Institute for Human Development. His main areas of expertise are decision making within management and leadership as well as behavioral economics. 
Gerd Gigerenzer is Director at the Max Planck Institute for Human Development and Director of the Harding Center for Risk Literacy in Berlin. He is former Professor of Psychology at the University of Chicago and John M. Olin Distinguished Visiting Professor, School of Law at the University of Virginia. He is also Batten Fellow at the Darden Business School, University of Virginia, and Fellow of the Berlin-Brandenburg Academy of Sciences and the German Academy of Sciences. Awards for his work include the AAAS Prize for the best article in the behavioral sciences and the Association of American Publishers Prize for the best book in the social and behavioral sciences. Gigerenzer has trained U.S. federal judges, German physicians, and top managers in decision making and understanding risks and uncertainties.

Jürgen Weibler $\mathrm{PhD}$, is a full professor of business administration, leadership, and organization at the University of Hagen (FernUniversität in Hagen), Germany. For many years, he was the research director of the Institute for Leadership and Human Resource Management at the University of St. Gallen, Switzerland, and was later professor for management at the University of Constance, Germany, as well a guest professor at MGSM, Sydney. He was also the founding senator of the German Police University. Besides he has served as a consultant to numerous organizations and has been engaged in different programs on further education in management. In his research, he focuses on leadership, organizational change, and ethics.

\section{References}

Achleitner, A.-K., Lutz, E., Mayer, J., \& Spiess-Knafl, W. (2012). Disentangling gut feeling: Assessing the integrity of social entrepreneurs. VOLUNTAS: International Journal of Voluntary and Nonprofit Organizations, 24(1), 93-124. doi:10.1007/ s11266-012-9264-2

Akinci, C., \& Sadler-Smith, E. (2012). Intuition in management research: A historical review. International Journal of Management Reviews, 14(1), 104-122. doi:10.1111/j.1468-2370.2011.00313.x

Albar, F. M., \& Jetter, A. J. (2013). Fast and frugal heuristics for new product screening-Is managerial judgment "good enough?" International Journal of Management and Decision Making, 12(2), 165-189.

Alby, F., \& Zucchermaglio, C. (2006). "Afterwards we can understand what went wrong, but now let's fix it": How situated work practices shape group decision making. Organization Studies, 27(7), 943-966. doi:10.1177/0170840606065703

Artinger, F., \& Gigerenzer, G. (2012). Pricing in an uncertain market. Working Paper. Max Planck Institute for Human Development.

Åstebro, T., \& Elhedhli, S. (2006). The effectiveness of simple decision heuristics: Forecasting commercial success for earlystage ventures. Management Science, 52(March), 395-409. doi:10.1287/mnsc.1050.0468

Barney, J. B. (1986). Strategic factor markets: Expectations, luck, and business strategy. Management Science, $32,1231-1241$. doi:10.1287/mnsc.32.10.1231

Baron, R. A., \& Ensley, M. D. (2006). Opportunity recognition as the detection of meaningful patterns: Evidence from comparisons of novice and experienced entrepreneurs. Management Science, 52, 1331-1344. doi:10.1287/ mnsc. 1060.0538

Baum, R. J., \& Wally, S. (2003). Strategic decision speed and firm performance. Strategic Management Journal, 24(11), 1107-1129. doi:10.1002/smj.343

Bazerman, M. H., \& Moore, D. A. (2008). Judgment in managerial decision making. New York: Wiley.

Ben-David, I., Graham, J. R., \& Campbell, R. H. (2013). Managerial miscalibration. The Quarterly Journal of Economics, 128 (4), 1547-1584. doi:10.1093/qje/qjt023.Advance

Berg, N. (2014). Success from satisficing and imitation: Entrepreneurs' location choice and implications of heuristics for local economic development. Journal of Business Research, 67(8), 1700-1709. doi:10.1016/j.jbusres.2014.02.016

Bhave, M. P. (1994). A process model of entrepreneurial venture creation. Journal of Business Venturing, 9, $223-242$. doi:10.1016/0883-9026(94)90031-0

Bingham, C. B., \& Eisenhardt, K. M. (2011). Rational heuristics: The "simple rules" that strategists learn from process experience. Strategic Management Journal, 32, 1437-1464. doi:10.1002/smj

Bingham, C. B., Eisenhardt, K. M., \& Furr, N. R. (2007). What makes a process a capability? Heuristics, strategy, and effective capture of opportunities. Strategic Entrepreneurship Journal, 1, 27-47. doi:10.1002/sej

Blattberg, R. C., \& Hoch, S. J. (1990). Database models and managerial intuition: 50\% model + 50\% manager. Management Science, 36(8), 887-899.

Boyd, R., \& Richerson, P. J. (2005). Solving the puzzle of human cooperation. Evolution and culture, $105-132$. 
Brighton, H. (2006). Robust inference with simple cognitive models. In C. Lebiere \& R. Wray (Eds.), AAAI spring symposium: Cognitive science principles meet AI-hard problems (pp. 17-22). Menlo Park, CA: American Association for Artificial Intelligence.

Brown, S., \& Eisenhardt, K. (1997). The art of continuous change: Linking complexity theory and time-paced evolution in relentlessly shifting organizations. Administrative Science Quarterly, 42(1), 1-34.

Busenitz, L., \& Barney, J. (1997). Differences between entrepreneurs and managers in large organizations: Biases and heuristics in strategic decision-making. Journal of Business Venturing, 12(1), 9-30.

Chase, W. G., \& Simon, H. A. (1973). Perception in chess. Cognitive Psychology, 4, 55-81.

Cohen, M. D., Burkhart, R., Dosi, G., Egidi, M., Marengo, L., Warglien, M., \& Winter, S. (1996). Routines and other recurring action patterns of organizations: Contemporary research issues. Industrial and Corporate Change, 5(3), 653-698. doi:10.1093/icc/5.3.653

Coleman, L., Maheswaran, K., \& Pinder, S. (2010). Narratives in managers' corporate finance decisions. Accounting \& Finance, 50(3), 605-633. doi:10.1111/j.1467-629X.2010.00343.x

Conolly, T. (1977). Information processing and decision making in organizations. In B. Staw \& G. Salancik (Eds.), New directions in organizational behavior (pp. 205-234). Chicago, IL: St. Clair Press.

Cyert, R., \& March, J. G. (1992). The behavioral theory of the firm. New York, NY: Wiley.

Czerlinski, J., Gigerenzer, G., \& Goldstein, D. G. (1999). How good are simple heuristics? In G. Gigerenzer, P. M. Todd, \& the ABC Research Group (Eds.), Simple heuristics that make us smart (pp. 97-118). New York, NY: Oxford University Press.

Davis, J. P., Eisenhardt, K. M., \& Bingham, C. B. (2009). Optimal structure, market dynamism, and the strategy of simple rules. Administrative Science Quarterly, 54(3), 413-452. doi:10.2189/asqu.2009.54.3.413

Dawes, R. M., \& Corrigan, B. (1974). Linear models in decision making. Psychological Bulletin, 81(2), 95-106.

De Meyer, A. Loch, C. H., \& Pich, M. T. (2002). Managing project uncertainty: From variation to chaos. MIT Sloan Management Review, 43, 60-67.

DeMiguel, V., Garlappi, L., \& Uppal, R. (2009). Optimal versus naive diversification: How inefficient is the 1/N portfolio strategy? Review of Financial Studies, 22(5), 1915-1953. doi:10.1093/rfs/hhm075

Dhami, M. K. (2003). Psychological models of professional decision making. Psychological Science, 14(2), 175-180. doi:10.1111/1467-9280.01438

Dill, W. R. (1962). The impact of environment on organizational development. In S. Mailick \& E. H. Van Ness (Eds.), Concepts and issues in administrative behavior (pp. 29-48). Englewood Cliffs, N.J.: Prentice-Hall.

Drummond, H. (2001). The art of decision making: Mirrors of imagination, masks of fate. Chichester, U.K.: Wiley.

Duncan, R. B. (1972). Characteristics of organizational environments and perceived environmental uncertainty. Administrative Science Quarterly, 17(3), 313-327.

Einhorn, H. J., \& Hogarth, R. M. (1975). Unit weighting schemes for decision making. Organizational Behavior and Human Performance, 13, 171-192.

Ford, J. K. K., Schmitt, N., Schechtman, S. L., Hults, B. M., \& Doherty, M. L. (1989). Process tracing methods: Contributions, problems, and neglected research questions. Organizational Behavior and Human Decision Processes, 43(1), 75-117. doi:10.1016/0749-5978(89)90059-9

Gary, M., Wood, R., \& Pillinger, T. (2012). Enhancing mental models, analogical transfer, and performance in strategic decision making. Strategic Management Journal, 33(11), 1229-1246. doi:10.1002/smj

Gavetti, G. (2005). Cognition and hierarchy: Rethinking the microfoundations of capabilities Development. Organization Science, 16(6), 599-617. doi:10.1287/orsc.1050.0140

Gavetti, G., Levinthal, D. A., \& Rivkin, J. W. (2005). Strategy making in novel and complex worlds: The power of analogy. Strategic Management Journal, 26(8), 691-712. doi:10.1002/smj.475

Geman, S., Bienenstock, E., \& Doursat, R. (1992). Neural networks and the bias-variance dilemma. Neural Computation, 4, 1-58.

Gigerenzer, G. (2014). Risk Savvy: How to make good decisions. New York, NY: Viking.

Gigerenzer, G., \& Brighton, H. J. (2009). Homo heuristicus: Why biased minds make better inferences. Topics in Cognitive Science, 1(1), 107-143. doi:10.1111/j.1756-8765.2008.01006.x

Gigerenzer, G., \& Gaissmaier, W. (2011). Heuristic decision making. Annual Review of Psychology, 62, 451-482. doi:10.1146/ annurev-psych-120709-145346

Gigerenzer, G., \& Goldstein, D. G. (1996). Reasoning the fast and frugal way: Models of bounded rationality. Psychological Review, 103(4), 650-669.

Gigerenzer, G., \& Goldstein, D. G. (2011). The recognition heuristic : A decade of research. Judgment and Decision Making, 6 (1), 100-121.

Gigerenzer, G., Hoffrage, U., \& Goldstein, D. G. (2008). Fast and frugal heuristics are plausible models of cognition: Reply to Dougherty, Franco-Watkins, and Thomas (2008). Psychological Review, 115, 230-239.

Gigerenzer, G., Todd, P. M., \& the ABC Research Group. (1999). Simple heuristics that make us smart (1st ed.). New York, NY: Oxford University Press. 
Goldstein, D., \& Gigerenzer, G. (2002). Models of ecological rationality: The recognition heuristic. Psychological Review, 109 (1), 75-90. doi:10.1037//0033-295X.109.1.75

Groner, M., Groner, R., \& Bischof, W. F. (1983). Approaches to heuristics: A historical review. In R. Groner, M. Groner, \& W. F. Bischof (Eds.), Methods of heuristics (pp. 1-18). Hillsdale, NJ: Erlbaum.

Guercini, S. (2012). New approaches to heuristic processes and entrepreneurial cognition of the market. Journal of Research in Marketing and Entrepreneurship, 14(2), 199-213. doi:10.1108/14715201211271410

Hills, G. E., \& Shrader, R. C. (1998). Successful entrepreneurs' insights into opportunity recognition. In P. D. Reynolds (Ed.), Frontiers of entrepreneurship research (pp. 30-43). Wellesley, MA: Babson College.

Hodgkinson, G. P., \& Healey, M. P. (2011). Psychological foundations of dynamic capabilities: Reflexion and reflection in strategic management. Strategic Management Journal, 32, 1500-1516. doi:10.1002/smj

Hodgkinson, G. P., \& Wright, G. (2002). Confronting strategic inertia in a top management team: Learning from failure. Organization Studies, 23(6), 949-977. doi:10.1177/0170840602236014

Hogarth, R. M. (2001). Educating intuition. Chicago, IL: The University of Chicago Press.

Hogarth, R. M., \& Karelaia, N. (2005). Ignoring information in binary choice with continuous variables: When is less "more"? Journal of Mathematical Psychology, 49(2), 115-124. doi:10.1016/j.jmp.2005.01.001

Hogarth, R. M., \& Karelaia, N. (2006). Regions of rationality: Maps for bounded agents. Decision Analysis, 3(3), 124-144.

Hogarth, R. M., \& Karelaia, N. (2007). Heuristic and linear models of judgment: Matching rules and environments. Psychological Review, 114(3), 733-58. doi:10.1037/0033-295X.114.3.733

$\mathrm{Hu}$, S., Blettner, D., \& Bettis, R. (2011). Adaptive aspiration performance: Performance consequences of risk preferences at extremes and alternative reference groups. Strategic Management Journal, 32, 1426-1436. doi:10.1002/smj

Jarzabkowski, P., \& Kaplan, S. (2014). Strategy tools-in-use: A framework for understanding "technologies of rationality" in practice. Strategic Management Journal, tba, tba. doi:10.1002/smj.2270

Jones, D., \& Martens, M. (2009). The mediating role of overall fairness and the moderating role of trust certainty in justicecriteria relationships: The formation and use of fairness heuristics in the workplace. Journal of Organizational Behavior, 30, 1025-1051. doi:10.1002/job

Kahneman, D. (1991). Judgment and decision making: A personal view. Psychological Science, 2, $142-145$.

Kahneman, D. (2011). Thinking, fast and slow. London: Macmillan.

Kahneman, D., \& Klein, G. (2009). Conditions for intuitive expertise: A failure to disagree. The American Psychologist, 64(6), 515-26. doi:10.1037/a0016755

Katsikopoulos, K. V., Schooler, L. J., \& Hertwig, R. (2010). The robust beauty of ordinary information. Psychological Review, 117(4), 1259-1266. doi:10.1037/a0020418

Khatri, N., \& Ng, H. A. (2000). The role of intuition in strategic decision making. Human Relations, 53(1), 57-86. doi:10.1177/ 0018726700531004

Klein, G. A. (1998). Sources of power: How people make decisions. Cambridge, MA: MIT Press.

Klein, G. A., Calderwood, R., \& Clinton-Cirocco, A. (1986). Rapid decision making on the fireground. In Proceedings of the Human Factors and Ergonomics Society 30th Annual Meeting (pp. 576-580). Norwood, NJ: Ablex.

Knight, F. H. (1921). Risk, uncertainty and profit. Boston, MA: Hart, Schaffner \& Marx; Houghton Mifflin Co.

Koberg, C. S., \& Ungson, G. R. (1987). The effects of environmental uncertainty and dependence on organizational structure and performance: A comparative study. Journal of Management, 13(4), 725-737. doi:10.1177/ 014920638701300412

Kohli, R., \& Jedidi, K. (2007). Representation and inference of lexicographic preference models and their variants. Marketing Science, 26(3), 380-399. doi:10.1287/mksc.1060.0241

Konovsky, M. A. (2000). Understanding procedural justice and its impact on business organizations. Journal of Management, 26 (3), 489-511. doi:10.1177/014920630002600306

Lant, T. K. (1992). Aspiration level adaptation: An empirical exploration. Management Science, 38(5), $623-644$.

Lawrence, P., \& Lorsch, J. (1967). Organization and environment. Managing differentiation and integration. Organization and environment. Boston, MA: Harvard Business School Press.

Lei, D., Slocum, J. W., \& Pitts, R. A. (1999). Designing organizations for competitive advantage: The power of unlearning and learning. Organizational Dynamics, 28(3), 24-38.

Levinthal, D. A. (1991). Random walks and organizational mortality. Administrative Science Quarterly, 36(3), $397-420$.

Levinthal, D. (1994). Surviving Schumpeterian environments: An evolutionary perspective. In J. A. C. Baum \& J. V. Singh (Eds.), Evolutionary dynamics of organizations (pp. 167-178). New York, NY: Oxford University Press.

Levinthal, D. (1997). Adaptation on rugged landscapes. Management Science, 43(7), 934-950.

Levitt, B., \& March, J. G. (1988). Organizational learning. Annual review of sociology, 319-340.

Lind, E., \& Kulik, C. (1993). Individual and corporate dispute resolution: Using procedural fairness as a decision heuristic. Administrative Science Quarterly, 38(2), 224-251. 
Lipshitz, R., Klein, G., Orasanu, J., \& Salas, E. (2001). Taking stock of naturalistic decision making. Journal of Behavioral Decision Making, 14(5), 331-352. doi:10.1002/bdm.381

Lovallo, D., Clarke, C., \& Camerer, C. F. (2012). Robust analogizing and the outside view: Two empirical tests of case-based decision making. Strategic Management Journal, 33, 496-512. doi:10.1002/smj.962

Luan, S., Schooler, L. J., \& Gigerenzer, G. (2011). A signal-detection analysis of fast-and-frugal trees. Psychological Review, 118 (2), 316-38. doi:10.1037/a0022684

Lumpkin, G. T., \& Lichtenstein, B. B. (2005). The role of organizational learning in the opportunity-recognition process. Entrepreneurship: Theory and Practice, 29, 451-472. doi:10.1111/j.1540-6520.2005.00093.x

Maidique, M. (2011). A leader's toolbox. Unpublished manuscript.

Maitland, E., \& Sammartino, A. (2014). Decision-making and uncertainty: The role of heuristics and experience in assessing a politically hazardous environment. Strategic Management Journal, tba, tba. doi:10.1002/smj.2297

Manimala, M. J. (1992). Entrepreneurial heuristics: A comparison between high PI (pioneering-innovative) and low PI ventures. Journal of Business Venturing, 7, 477-504.

March, J. G., \& Olsen, J. P. (1986). Garbage can models of decision making in organizations. In J. D. March \& R. WeissingerBaylon (Eds.), Ambiguity and command. Organizational perspectives on military decision making. (pp. 11-35). Marshfield, WI: White Plans.

March, J. G., \& Simon, H. A. (1993). Organizations revisited. Industrial and Corporate Change, 2(3), $299-316$.

Marewski, J. N., \& Schooler, L. J. (2011). Cognitive niches: An ecological model of strategy selection. Psychological Review, 118(3), 393-437. doi:10.1037/a0024143

Martignon, L., \& Hoffrage, U. (2002). Fast, frugal, and fit: Simple heuristics for paired comparison. Theory and Decision, 52(1), 29-71. doi:10.1023/A:1015516217425

Martignon, L., Katsikopoulos, K. V., \& Woike, J. K. (2008). Categorization with limited resources: A family of simple heuristics. Journal of Mathematical Psychology, 52(6), 352-361. doi:10.1016/j.jmp.2008.04.003

McMullen, J., \& Shepherd, D. (2006). Entrepreneurial action and the role of uncertainty in the theory of the entrepreneur. Academy of Management Review, 31(1), 132-152.

Medin, D., Goldstone, R., \& Gentner, D. (1993). Respects for similarity. Psychological Review, 100(2), 254-278

Meehl, P. E. (1954). Clinical versus statistical prediction: A theoretical analysis and a review of the evidence. Minneapolis, MN: University of Minnesota Press.

Messick, D. M. (1993). Equality as a decision heuristic. In B. A. Mellers \& J. Barn (Eds.), Psychological perspectives on justice: Theories and application (pp. 11-31). Cambridge, NY: Cambridge University Press.

Messick, D. M. (1999). Alternative logics for decision making in social settings. Journal of Economic Behavior \& Organization, 39(1), 11-28. doi:10.1016/S0167-2681(99)00023-2

Mezias, S. J., Chen, Y., Murphy, P. R., \& Patrice, Y. C. (2002). Aspiration-level adaptation in American financial services organization: A field study. Management Science, 48(10), 1285-1300.

Mezias, J. M., \& Starbuck, W. H. (2003). Studying the accuracy of managers' perceptions: A research odyssey. British Journal of Management, 14(1), 3-17. doi:10.1111/1467-8551.00259

Mingers, J., \& White, L. (2010). A review of the recent contribution of systems thinking to operational research and management science. European Journal of Operational Research, 207(3), 1147-1161. doi:10.1016/j.ejor.2009.12.019

Mintzberg, H. (1978). Patterns in strategy formation. Management Science, 24(9), 934-948.

Muramatsu, R., \& Hanoch, Y. (2005). Emotions as a mechanism for boundedly rational agents: The fast and frugal way. Journal of Economic Psychology, 26(2), 201-221.

Murphy, G., \& Medin, D. (1985). The role of theories in conceptual coherence. Psychological Review, 92(3), $289-316$.

Nelson, R. R., \& Winter, S. G. (1982). An evolutionary theory of economic change. Cambridge, MA: Belknap Press.

Oliver, D., \& Roos, J. (2005). Decision-making in high-velocity environments: The importance of guiding principles. Organization Studies, 26, 889-913. doi:10.1177/0170840605054609

Osgood, C. (1949). The similarity paradox in human learning: A resolution. Psychological Review, 56(3), $132-143$.

Payne, J. W., Bettman, J. R., \& Johnson, E. J. (1992). The adaptive decision maker. Cambridge, MA: Cambridge University Press.

Payne, J. W., Bettman, J. R., \& Johnson, E. J. (1993). The use of multiple strategies in judgment and choice. In N. J. Castellan (Ed.), Individual and group decision making: Current issues. (pp. 19-39). Hillsdale, NJ: Lawrence Erlbaum Associates.

Perkins, E. J. (1999). Wall street to main street. New York: Cambridge University Press.

Polya, G. (1954). Mathematics and plausible reasoning. Vol. 1: Induction and analogy in mathematics. Princeton, NJ: Princeton University Press.

Porter, M. E. (1996). What is strategy? Harvard Business Review, 74(6), 61-78.

Powell, T. C. (2003). Varieties of competitive parity. Strategic Management Journal, 24(1), 61-86. doi:10.1002/smj.283

Powell, T. C., Lovallo, D., \& Fox, C. R. (2011). Behavioral strategy. Strategic Management Journal, $32,1369-1386$. doi:10.1002/smj 
Read, D., \& Grushka-Cockayne, Y. (2011). The similarity heuristic. Journal of Behavioral Decision Making, $24(1), 23-46$. doi:10.1002/bdm.679

Reijers, H. A., \& Liman Mansar, S. (2005). Best practices in business process redesign: An overview and qualitative evaluation of successful redesign heuristics. Omega, 33(4), 283-306. doi:10.1016/j.omega.2004.04.012

Rieskamp, J., \& Otto, P. E. (2006). SSL: A theory of how people learn to select strategies. Journal of Experimental Psychology: General, 135, 207-236. doi:10.1037/0096-3445.135.2.207

Rivkin, J. W., \& March, J. G. (2000). Imitation of complex strategies. Management Science, 46(6), 824-844. doi:10.1287/ mnsc.46.6.824.11940

Rusetski, A. (2014). Pricing by intuition: Managerial choices with limited information. Journal of Business Research, 67(8), 1733-1743. doi:10.1016/j.jbusres.2014.02.020

Salter, M. (2003). Innovation corrupted: The rise and fall of Enron. Harvard Business School Working Paper No. 03-077.

Selten, R. (1998). Aspiration adaptation theory. Journal of Mathematical Psychology, 42, 191-214.

Siggelkow, N. (2002). Evolution toward fit. Administrative Science Quarterly, 47, 125-159.

Simon, H. A. (1955). A behavioral model of rational choice. The Quarterly Journal of Economics, 69(1), 99-118.

Simon, H. A. (1956). Rational choice and the structure of the environment. Psychological Review, 63(2), 129-138. doi:10.1037/ h0042769

Simon, H. A., \& Newell, A. (1958). Heuristic problem solving: The next advance in operations research. Operations Research, $6(1), 1-10$.

Simsek, O. (2013). Linear decision rule as aspiration for simple decision heuristics. Advances in Neural Information Processing Systems, 26, 2904-2912.

Slovic, P., Finucane, M. L., Peters, E., \& MacGregor, D. G. (2007). The affect heuristic. European Journal of Operational Research, 177(3), 1333-1352.

Stemberg, T. (1996). Staples for success: From business plan to billion-dollar business in just a decade. Santa Monica, CA: Knowledge Exchange.

Stigler, G. J. (1961). The economics of information. The Journal of Political Economy, 69(3), $213-225$.

Teece, D. J., Pisano, G., \& Shuen, A. (1997). Dynamic capabilities and strategic management. Strategic Management Journal, 8 (7), 509-533.

Thorndike, E. L. (1931). Human learning. New York, NY: Century.

Todd, P. M. (2000). Ecological rationality and its contents. Thinking and Reasoning, 6, 375-384.

Todd, P. M., Gigerenzer, G., \& the ABC Research Group. (2012). Ecological rationality: Intelligence in the world. New York, NY: Oxford University Press.

Tripsas, M., \& Gavetti, G. (2000). Capabilities, cognition, and inertia: Evidence from digital imaging. Strategic Management Journal, 21, 1147-1161.

Tversky, A. (1972). Elimination by aspects: A theory of choice. Psychological Review, 79(4), 281-299. doi:10.1037/ h0032955

Tversky, A. (1977). Features of similarity. Psychological Review, 84(4), 327-352.

Tversky, A., \& Kahneman, D. (1974). Judgment under uncertainty: Heuristics and biases. Science, 185(4157), $1124-31$. doi:10.1126/science.185.4157.1124

Vaara, E., \& Whittington, R. (2012). Strategy-as-practice: Taking social practices seriously. The Academy of Management Annals, 6(1), 285-336.

Vroom, V. H., \& Yetton, P. W. (1973). Leadership and decision-making. Pittsburgh, PA: University of Pittsburgh Press.

Weick, K. E. (1995). Sensemaking in organizations. London: SAGE Publications.

Wübben, M., \& von Wangenheim, F. (2008). Instant customer base analysis: Managerial heuristics often "get it right." Journal of Marketing, 72, 82-93.

Yee, M., Dahan, E., Hauser, J. R., \& Orlin, J. (2007). Greedoid-based noncompensatory inference. Marketing Science, 26(4), 532-549. doi:10.1287/mksc. 1060.0213 